\title{
A Systematic Review of Past Decade of Mobile Learning: What we Learned and Where to Go
}

\author{
https://doi.org/10.3991/ijim.v14i06.13479 \\ Muhammad Imran Qureshi ${ }^{(凶)}$ \\ Universiti Teknikal Malaysia Melaka, Melaka, Malaysia \\ qureshi@utem.edu.my \\ Nohman Khan \\ University of Kuala Lumpur, Kuala Lumpur, Malaysia \\ Syed Muhammad Ahmad Hassan Gillani, Hamad Raza \\ University Teknologi Malaysia, Kuala Lampur, Malaysia
}

\begin{abstract}
The increasing growth of mobile technology in our Society has become a reality. Outdoor learning is one of the very revolutionary developments in modern ages without huge infrastructure and resources. This study is focusing the area of mobile learning in year 2009 to 2018 about the areas and working done by the researchers. Mobile learning is relatively a new platform of learning through the mobile technologies, and penetration of smartphones and digital devices is globally increased in a short interval of time. The Scopus database is used to find the literature with the keyword used in search button mobile learning. The PRISMA diagram 2009 shows that the subjects of Social Sciences area to include the literature articles for the review. The final 54 articles with more than 20 citations for the review are selected to analyze the literature to find the gap and direction of mobile learning. Literature is divided in different classifications to find the results.
\end{abstract}

Keywords-Mobile learning, Ubiquitous Learning Environments, pedagogical

\section{Introduction}

Outdoor learning is one of the very revolutionary developments in modern ages without huge infrastructure and resources. The traditional concept of education and learning is about to change, technological advancement and IR 0.4 enhance the structure of learning through devices such as laptops, tablets, and smartphones. The devices have not inside the classroom but outside have great potential for learning [1]-[17]

[18]. Relatively mobile learning is new phenomenon, but the effectiveness of the tool is countless in terms of high-quality education and learning process. A smartphone is not only a phone but a device that can educate you with your willingness and timing that is conveniently available for the user [19]. Digital mobile technology using in educational purposes is the core function of vibrant and expanding 
streams of mobile learning research and that is called ubiquitous learning. With the ubiquitous learning teachers are looking and exploring the technologies that are combining mobile devices with collaborative learning environment in process to enhance learning [20].With the period mobile learning is growing more and technological advancement opening create opportunity for students to educate in every field. This study will review the mobile learning approaches direction and significance in distance learning and classify the fields in which mobile learning is contributing effectively with high performance. Mobile learning is a greater solution for the developing and under-developing countries to educate large masses without the giant infrastructure development and only manage the techniques and applications with smartphones and other mobile devices that can assist students in distance areas [21]. Educating the outdoor student specifically online courses are more effective for different corners and learning new technologies, new languages and mathematical tools, mobile learning is very effective [21].

Educational techniques are changing very quickly, and another form of mobile learning is moving forward toward the e-learning applications that make possible much easier for students to approach desire text and solution of problem [22]. Mobile learning makes possible for students to learn, collaborate, and share ideas through the internet and m-learning system. M-learning modified form of learning in which mobile applications are making more diverse and accurate information available according to the need of students [23]. That is more comfortable for the learners to download the app and use that according to the need and share the ideas and views with the other users about the applications. But some of the characteristics of m-learning applications can also contribute for the teachers the way they teach to students and an important feature of m-learning is the traditional transfer of knowledge from teacher to student is changed and students can actively participate in the learning process [24]. Before that the educational structure was teacher-centered and after the mobile technology's developments make this to student-centered. Researchers of m-health are believing in maximize the use of mobile technologies in the higher education level while going with the educational mission. Many researchers argued that in higher education levels, students and teachers are ambition in learning mobile technologies [25-27]

This study is focusing the area of mobile learning in year 2009 to 2018 about the areas and working done by the researchers. Mobile learning is relatively a new platform of learning through the mobile technologies, and penetration of smartphones and digital devices is globally increased in a short interval of time. We will overview the literature, how researchers contributed the area of mobile learning during the 10 years of time. We will classify the broad areas of research and look deeply the recommendations and findings of the literature in the field mobile learning. Study is conducted due to importance and effectiveness of mobile learning from educational point of view. The significance of the study is to evaluate the researchers work during the 10 years and direction of researchers. In the first step quality screening process will be complete through the PRISMA statement and inclusion and exclusion of literature will be done through the quality process of PRISMA statement. Second step will 
overview the classification of literature. The recommendations and conclusion will discuss in the last after the detail review process.

\section{Methodology}

The most recent attention of mobile learning is motivated researchers to work on the development of mobile learning in the recent years and this study will overview the literature towards the direction and missing areas of mobile learning for the educational development. The study analysis the past literature to a systematic literature review (SLR). The PRISMA statement templet is used to explain the overall process of selection and rejections of articles for the review of mobile learning. The PRISMA statement helps the researcher to improve the reporting of the review paper. The review is limited to published literature.

\section{$3 \quad$ Literature Research}

The Scopus database is used to find the literature with the keyword used in search button mobile learning. The total number of articles is shown by database 38772 , but when the research is limited to the year 2009 to 2018 the number is decreased to 27398. The process is needed to filter more for the quality of the review, the language is selected only English and subject are selected social sciences for assessment and numbers are reached to 7547. After this the other options used from Scopus database of only published articles the results are automatically limited to 33320 . There are other options like conference papers, review papers and submitted papers but for the reliability and quality of the study only published articles are included for the study. The PRISMA diagram 2009 shows that the subjects of Social Sciences area to include the literature articles for the review. For PRISMA diagram only open access articles of Scopus database is used for review and record are limited to 489 papers that were available in open access in Scopus database. The data is imported to excel sheets for further assessment of the literature. The excel sheets are extended into more sheets to find out the highest citations and for more batter and purified analysis, more than 20 citations papers are used for the study. after this the results are limited to 56 studies. The four studies are also excluded after the detail studies of the article's due irrelevancy with the subject. The final 54 articles for the review are selected to analyze the literature to find the gap and direction of mobile learning. 


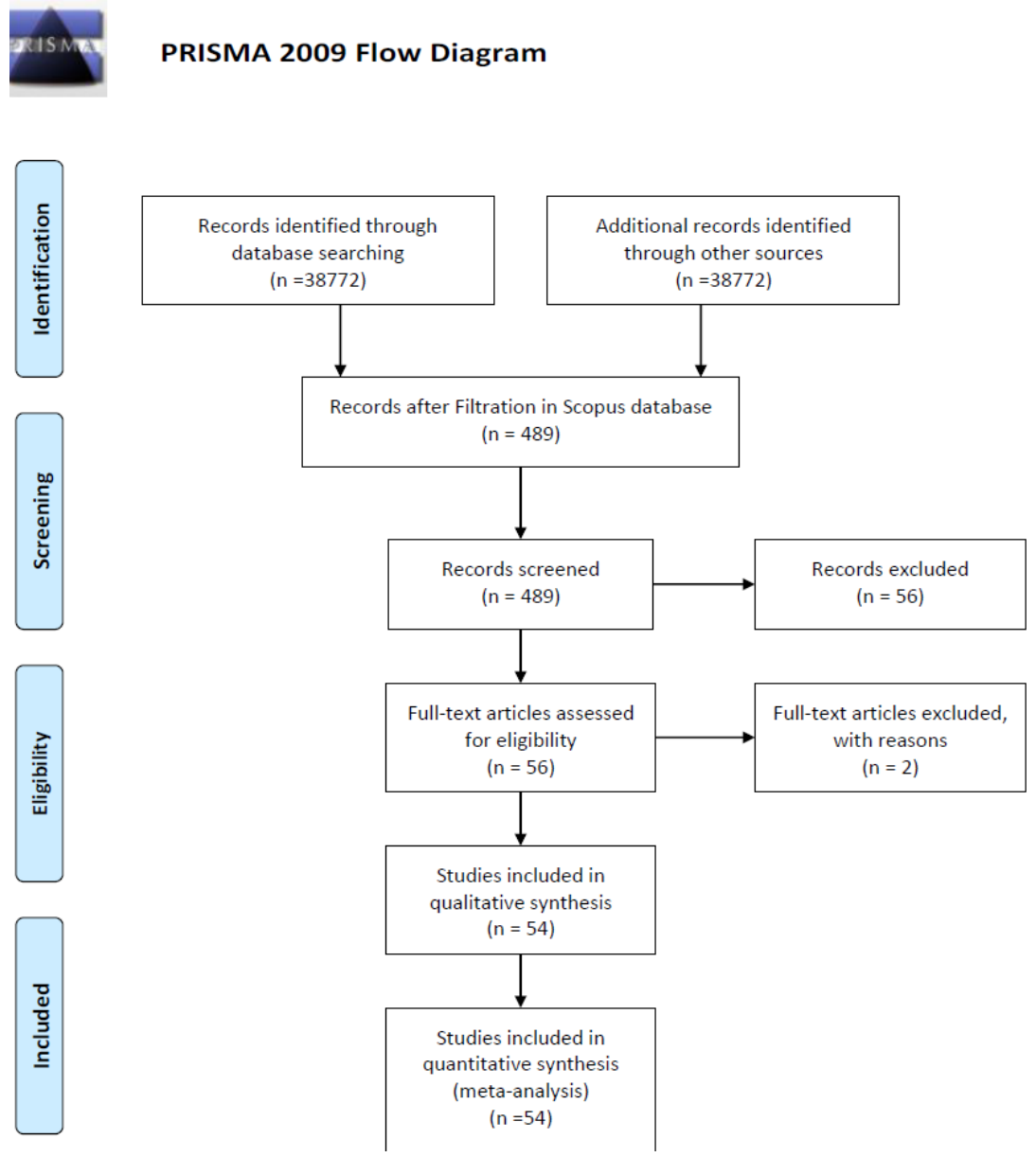

Fig. 1. PRISMA 2009 diagram of selection and screening process

\section{$4 \quad$ Eligibility and Inclusion Criteria}

The eligibility and inclusion of articles one of very critical and absolute observation way to include the best possible articles for the study. Generally, the language is selected for the articles is English and due to universal acceptability and maximum literature is published in English, so the articles are selected only in English language. The research article from the database is selected only from one subject social science. But also make sure the papers from all journals of the database must be considered for more batter and quality results. The open-access articles are considered for the review. 


\section{$5 \quad$ Studies Included in Qualitative Synthesis}

The final 54 studies are used for the final process and find the direction and research done by the researcher in the year 2009 to 2018 . The year base analysis is done to find out the annual publications and most cited papers are also be explained through the graph. the subject wise research is also explained in the graph to show the number of papers is include and exclude for the review. The journal base and most cited papers are also discussed

\section{$6 \quad$ Most Cited}

Minimum citation report of a paper in the study is 20 times and highest is 251 time of a paper. The effects of integrating mobile devices with teaching and learning on students' learning performance: A meta-analysis and research synthesis is cited 251 times which is a good number and other study with high citations number is Viewing mobile learning from a pedagogical perspective with the 232 times by the other studies. The citation criteria are making the study more valuable due to the other research's citations. Using mobile phones to improve educational outcomes: An analysis of evidence from Asia is the study 3rd number in the citation list with 150 times citation. Figure 1.2 is showing the details of citations report for more times and selected for the study.

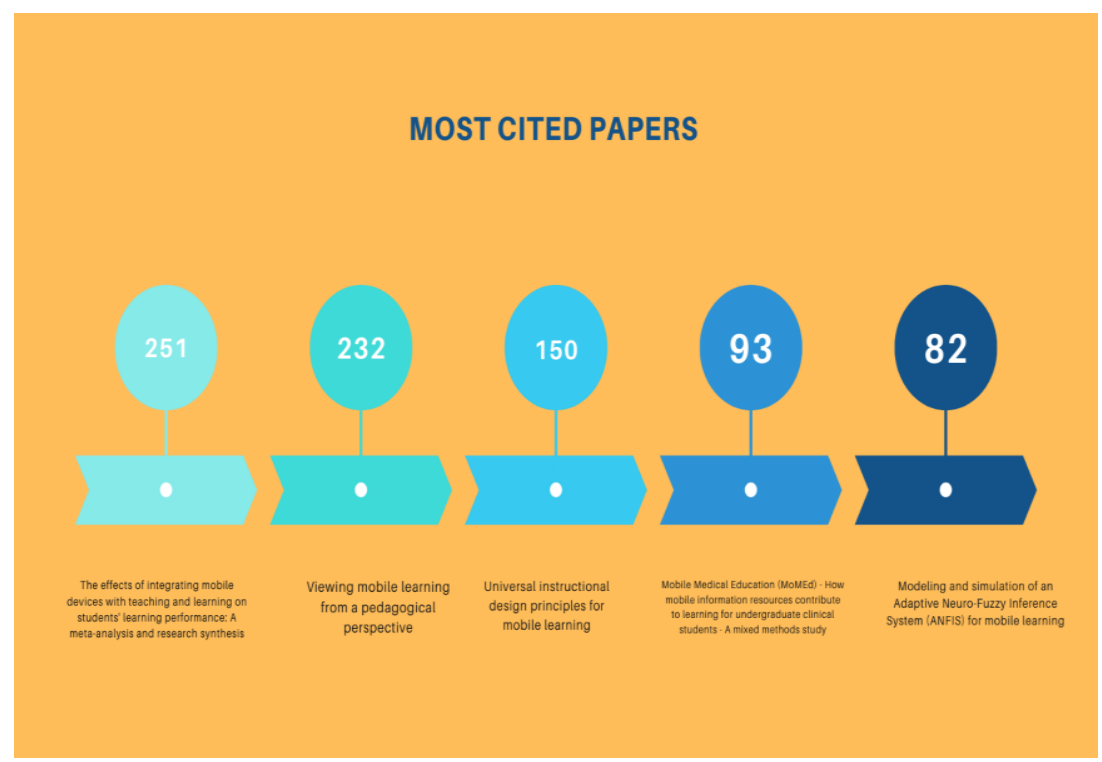

Fig. 2. most cited papers 


\section{$7 \quad$ Year Wise Publications}

The study is limited from year 2009 to 2018 and every year publications are different and selected papers are due to the characteristics of most citations. Year 2010 and 2015 is the top on the list with 11 studies elected for the review and minimum number of the studies are choose from year 2018 and 2017 with 1 paper each from every year. While year's 2014,2012 and 2011 are having 9,6 and 5 studies from each year with high citation report. Figure 1.3 is showing the complete number and results of 10 -year publications record selected for the study.

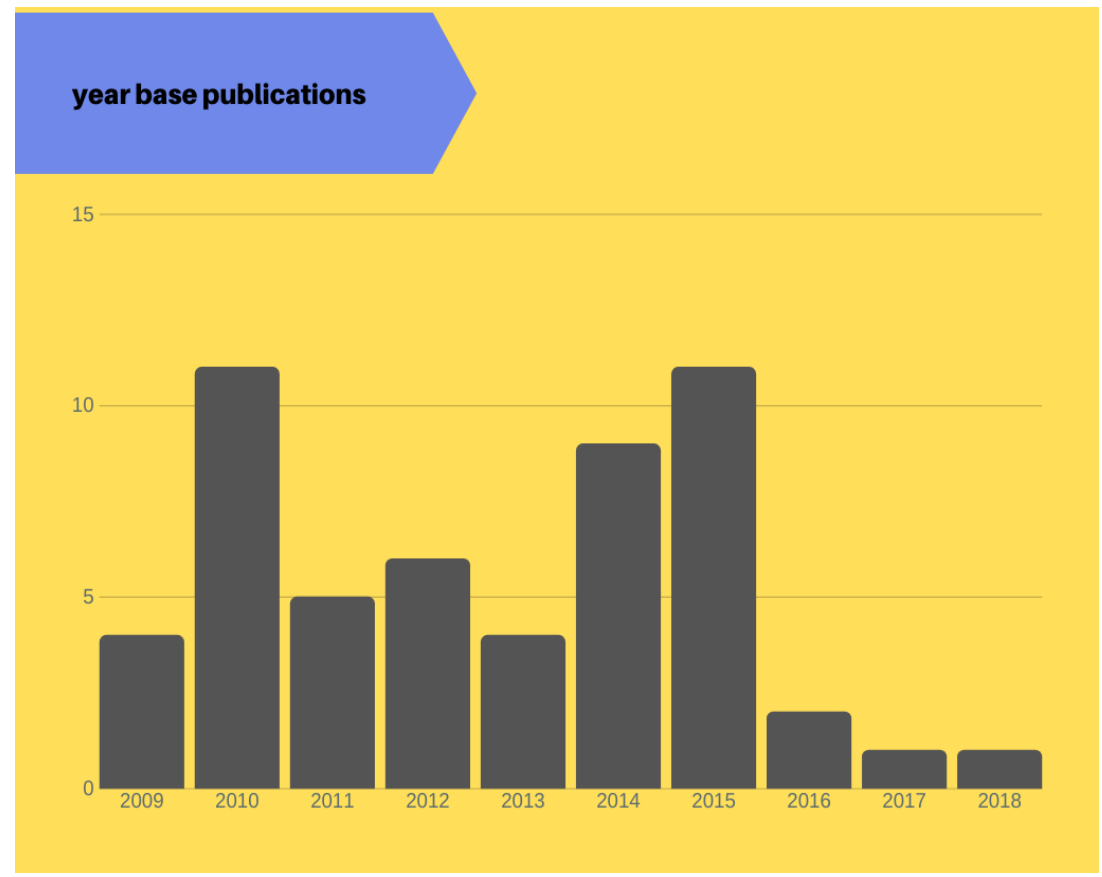

Fig. 3. Year base publications

\section{Journal Base Publications}

IEEE Transactions on Learning Technologies is journal that is top rank in selection criteria with 19 studies are selected from the journal. All studies are citation report more then 20 times and no other journal is near around the number of articles selected for this study. International Review of Research in Open and Distance Learning is the second in the list with the 6 studies choose for the review paper and citation report is more then times in other studies cited. Figure 1.4 is showing the highest number of papers selected from the different journals. BMC Medical Education is 3rd in the list with 4 articles selected through the screening process and citation is more than 20 times. 


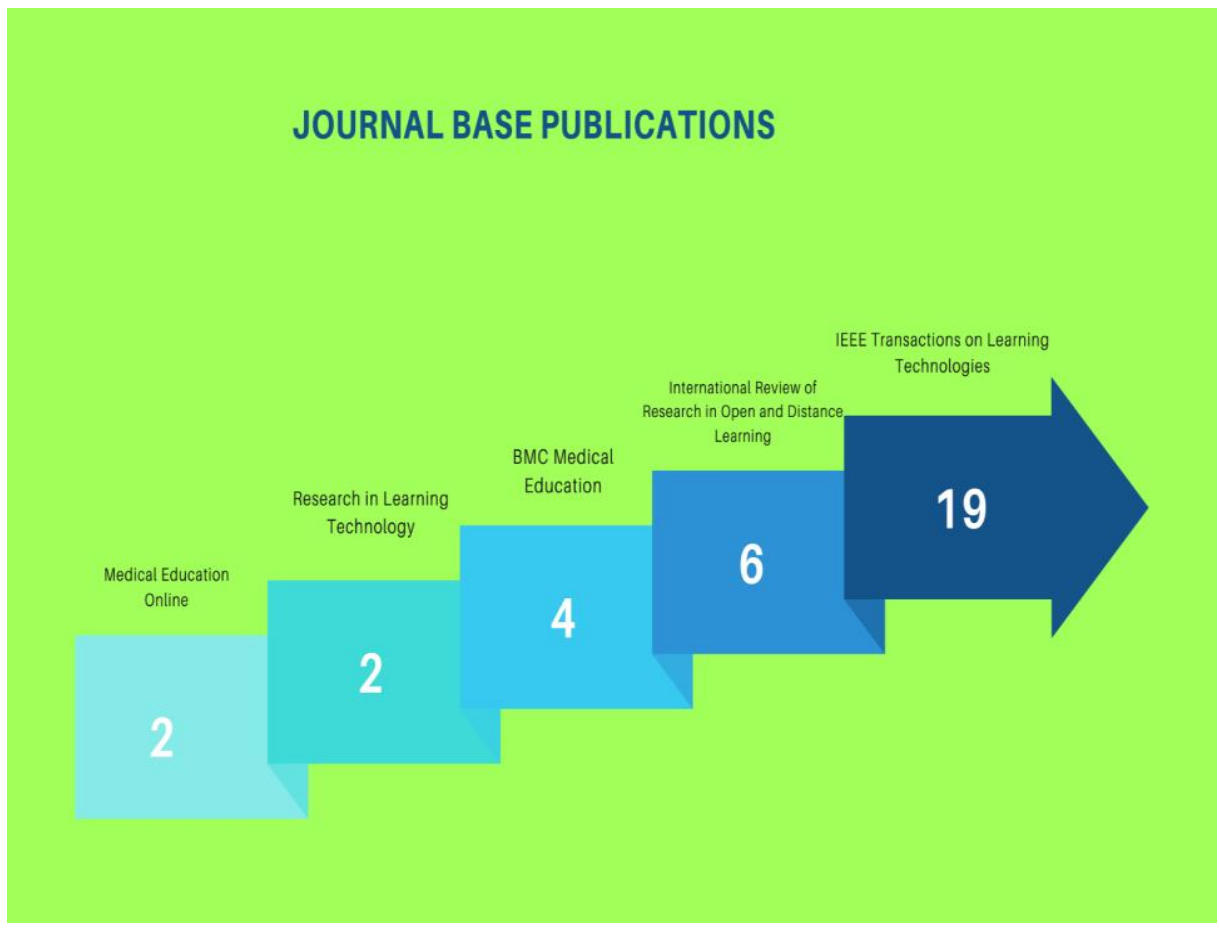

Fig. 4. Journal base publications

\section{Classifications}

Literature is classified in different areas according to the work done by the researchers and table 1.1 is showing the results of classifications.

\subsection{Mobile learning students and teachers}

The mobile learning classification process on excel sheet shows more contribution of the researcher is on student learning and teachers' responsibilities in distance learning and adjustable time frame according to the availability of students and teachers. Collaborative learning: Group interaction in an intelligent mobile-assisted multiple language learning system is the study that discuss the tutoring through the mobile phones and developing an effective intelligent tutoring system [28]. The findings of the study show that the learning through the mobile tutoring is effective and students can take advantage of the applications using mobile phones. Mobile learning environment is very important for students and teachers, in the environment students and teachers can work together in collaborative environment for user feature and context [29]. Supporting the Development of Mobile Adaptive Learning Environments: A Case Study recommended that the students and teachers work together for mobile learning environment development for the future prospectus. The effects of learning 
styles and meaningful learning on the learning achievement of gamification health education curriculum study is also talks about the procedures about the learning styles, meaning full learning and learning achievement. The study agenda was towards the junior high school learning students through the digital mobile game learning. The findings of the study are divergence in mobile game-based students are highly regarded the curriculum [30]. Another study explains the importance of the distance learning and suggest distance learning is opening new opportunities for away students and they are able to educate them through the mobile phones and Mobile learning: Moving past the myths and embracing the opportunities study also talks about the challenges and risks related to the mobile learning in the future [31]. Academic mobility and migration: What we know and what we do not know is the study that talks about the higher education and research base scholarly education for the teachers. The suggested that to use the mobile learning about the international techniques and research opportunities through the mobile technologies and make the research more valuable in other parts of world [32].

The mobile learning in students and teacher's classification is mostly literature is talking about the environment that helpful for learning. Future of mobile learning is very important in distance

Table 1. Classification of literature

\begin{tabular}{|c|c|c|}
\hline Authors & Variables & Findings \\
\hline $\begin{array}{l}\text { (Troussas, Virvou, \& Alepis, 2014) } \\
\text { [28] }\end{array}$ & $\begin{array}{l}\text { Mobile Learning Students and } \\
\text { Teachers }\end{array}$ & $\begin{array}{l}\text { Environments rich in opportunity } \\
\text { for self-regulated learning }\end{array}$ \\
\hline (Teichler, 2015) [32] & $\begin{array}{l}\text { Ubiquitous Learning Environments } \\
\text { (ULEs) }\end{array}$ & $\begin{array}{l}\text { Education beyond the traditional } \\
\text { classroom, creating so-called } \\
\text { Ubiquitous Learning Environments }\end{array}$ \\
\hline $\begin{array}{l}\text { (Kenny, Park, C Van Neste-Kenny, } \\
\text { Burton, \& Qayyum, [30], } \\
\text { Medhanyie et al., [31] }\end{array}$ & $\begin{array}{l}\text { Mobile health (mHealth) applica- } \\
\text { tions and Mobile Learning in } \\
\text { Patient Care }\end{array}$ & $\begin{array}{l}\text { M-Learning seek to provide an } \\
\text { overview of what mobile learning } \\
\text { entails, recognize the achievements } \\
\text { of mobile learning to date, and } \\
\text { stimulate }\end{array}$ \\
\hline $\begin{array}{l}\text { (G Sun, Technologies, 2014[32], } \\
\text { Boticki, Wong, Learning, \& } \\
\text { 2012[39] }\end{array}$ & Collaborative Learning & $\begin{array}{l}\text { Collaborative learning brought by } \\
\text { TaaS in real university level cours- } \\
\text { es }\end{array}$ \\
\hline (Yang, Learning, 2014, [35] & Foreign Language Learning & $\begin{array}{l}\text { Make cultural and language learn- } \\
\text { ing appealing, improve cultural } \\
\text { learning effectiveness, and enhance } \\
\text { interpersonal communication } \\
\text { between teachers and students }\end{array}$ \\
\hline $\begin{array}{l}\text { (Bower, Education, } 2015 \text { [36] } \\
\text { Kearney, Schuck, Burden, \& } \\
\text { Aubusson, 2012)[19] }\end{array}$ & $\begin{array}{l}\text { Wearable Technologies \& robot } \\
\text { technologies }\end{array}$ & $\begin{array}{l}\text { Future of wearable technology } \\
\text { learning design is also discussed }\end{array}$ \\
\hline $\begin{array}{l}\text { (Cochrane \& Antonczak, 2014, } \\
\text { Soep, 2012) [37] }\end{array}$ & Mobile Social Media & $\begin{array}{l}\text { Mobile social media framework is } \\
\text { potentially transferable to a range } \\
\text { of educational contexts, }\end{array}$ \\
\hline
\end{tabular}

Learning and students can learn about the technology and other segments related to the mobile learning very conveniently using the mobile phones. 


\subsection{Ubiquitous Learning Environments (ULEs)}

Second classification of the literature is about the ubiquitous learning environment, that is basically explains the penetration and accessibility of mobile learning in the last decade. Traditional classrooms and educational scope are completely changed into complex technologies and mobile devices. Supporting teacher orchestration in ubiquitous learning environments: A study in primary education discuss the ubiquitous learning environment in detail, Teichler [32] suggested that the resources and energies must be utilize to support for the primary level teachers that are performing in the complex model ubiquitous learning environment. Teachers able to perfume in more batter way. Another study Context-aware services for smart learning spaces suggested that in the literature about the removal of the traditional classrooms, labs, meeting rooms and halls into services centers that provide more effective and efficient learning opportunities to the students and curriculum should be design according to the mobile learning situations [38]. According to the author due to this system learners and instructors are easily communicate with each other on mobiles and all students can learn very effectively. Mobile learning is more effective in the mobile integrated and individualize course in an application. Individualization for education at Scale: MIIC design and preliminary evaluation is study that suggested the idea about the one application for the students learning through the ubiquitous learning environment and convert the course into the integrate lecture videos, text, assessment and social learning into application. That can update the student learning model and also measurement of the student behavioral measurement [38].

Mobile learning environment needs to improve the learning structure and content of the students and provide a batter learning environment for both instructors and learners. Mobile applications are more reliable and effective tools for mobile learning during the current times.

\subsection{Mobile health (mHealth) applications and mobile Learning in patient care}

A good number of literatures in year is discussing the patient care using the mobile learning care and more developed form of the mobile health in mHealth applications. Mobile Medical Education (MoMEd) - How mobile information resources contribute to learning for undergraduate clinical students - A mixed methods study talks about the students use mobile learning for the improvement of learning and experience of clinical area of patient care. Clinicians are rise the use of mobile technology for more updated knowledge for patient care this study suggested that healthcare other departments must adopt the mobile technologies for the improvement and development of the patientcare[38]. Medhanyie et al. [31] believes that health applications are very much important for the healthcare, specially the developing countries health sector could be improve using the mHealth applications. Author also recommended that healthcare workers in developing countries must be provide smartphones and technological advancement to use the mHealth applications for learning and personal development. International Review of Research in Open and Distance Learning study also suggested the mobile learning importance in nursing students and faculty. The study 
based on the survey and results of the suggested that the mobile learning improves the performance of the nursing students and faculty. Study also indicates that 75 out of 100 nursing students and faculty members are engage with the mobile learning [30]. Mobile learning is very much effective, and importance of healthcare is based on mobile learning. Medical students, doctors and nursing staff also must be equipped with the mobile learning due to the importance of mobile technologies.

\subsection{Collaborative learning}

In mobile learning that is very important to collaborate about the learning with the teams and individual for more development and penetration. Mobile learning is one of top emerging tend that is bringing many advantages for disturb learners. Collaborative learning is together the multiple learners together towards the pedagogical in online courses[32]. Designing technology for content-independent collaborative mobile learning study talks about the collaborative mobile learning opportunities and design the technology platform for motivating content mobile learning in the classroom. Technical architecture is assigning different materials to student and then guide all groups to achieve the preassign goals. Results of study recommended that the groups and teams are more batter in the mobile learning [39]. Collaborative learning is empowering the mobile learning and mobile applications are more strengthen the teams and goals of teams in mobile learning. Students are more learning in collaborative environment and mobile phones are more powerful tools for collaborative learning.

\subsection{Foreign language learning}

Mobile learning most attractive and easy tool to learn the foreign languages, Successful learning of academic word list via MALL: Mobile assisted language learning article discuss the importance of foreign languages learning in mobile learning. Study discuss that mobiles phones are a new addition in information and communication field for learners in the process of foreign languages learning. Results of the study recommended that teachers must send text messages to student about the language learning and they must in contact with each other [40] . mobile learning is also very helpful in cultural and language learning according to the Computer-assisted culture learning in an online augmented reality environment based on free-hand gesture interaction research article included in the study. Study objectives were about the improve cultural learning effectiveness and strengthen the interpersonal communication language between the students and teachers [35]. Mobile applications are a very effective and powerful tool of language learning due to the large number of videos, images and tutorial are available in different languages, that can help and guide in wright direction in learning the languages. Foreign language institutes are using the same techniques with students and courses they offer in foreign languages learning, they just collect videos and images to teach students through the mobile phones. 


\section{Wearable Technologies and Robot Technologies}

Wearable technologies are a new phenomenon of technology development and many educationalists are harness pedagogical opportunities to understanding their potentials. What are the educational affordances of wearable technologies? Article that is cited 74 times suggested that three emergent themes; 'pedagogical uses', 'educational quality' and 'logistical' in the research paper. Data is collected from educationalists and find that wearable technologies are more effective and important in the mobile learning and this is updated version of mobile learning in context of emails, reminders, massages and many other futures related with wearable devices [36]. Viewing mobile learning from a pedagogical perspective is study discuss the feature of mobile learning and devices used in mobile learning. Basically, mobile learning has three main features: authenticity, collaboration and personalization, for the mobile learning [19]. A mobile mixed-reality environment for children's storytelling using a handheld projector and a robot article describe the robot's technologies for storytelling to children's using robots. Findings of the study are robots enhance children's embodied participation in, and their level of engagement with, their storytelling activities, and can support children in designing and expressing creative and original stories.

\section{Mobile Social Media}

Social media provides a unique and creative opportunities for learning environment. Case studies literature is emerging from the mobile learning and social media, for confirmation of the literature a study "Implementing a mobile social media framework for designing creative pedagogies" conducted number of social media projects. Findings of the study are social media project is potentially transferable in context of mobile learning and new pedagogies [37]. Social media medium to educate and learn new information to educate and update. Distance areas are now connected with the social media very easily through the mobile networks. Mobile penetration is growing rapidly and now students are almost on every social media medium that can educate them. Languages learning students are comfortably contact with the other native language speakers and get feedback. Digital era of technology shaped the traditional institutional structure and mobile learning is premium tool in the learning process. The digital afterlife of youth-made media: Implications for media literacy education is article included in the study and describe the youth media importance for mobile learning process. paper conclude that youth is deliberate to contribute through the mediums of social and mobile media. They are highly interested in discovery, analytics, networking mobilization and platform program [42]. 


\section{Conclusion}

Education process is very much dependent on mobile learning and numerous of fields are growing the development of mobile learning. Literature discusses many prime fields and importance of mobile learning within the fields for improving the ability of students in learning process. mobile applications are now the new advancement of era in learning skills in every field and social media platform are strengthen the process. mobile applications are not only text and videos but also tutorials that are showing the actual processes. Study find that literature is directing quality of work in every field during the year 2009 to 2018 but literature is very limited about social media and mobile applications learning. Results are also indicating that researchers must work about mobile applications importance and value in mobile learning that will helpful for student and for teachers. Literature is contributing more about the teachers learning and development but missing the link about teachers training and teaching skills importance in mobile learning process. literature linking very few studies in sciences subjects and visual arts subjects in past years. The subjects are very important to teach and offer through the mobile learning and researchers need to identify the importance of the subjects.

\section{References}

[1] M. I. Qureshi et al., "Measuring the ecological footprint of inbound and outbound tourists: evidence from a panel of 35 countries," Clean Technol. Environ. Policy, 2019. https://doi. org/10.1007/s10098-019-01720-1

[2] M. I. Qureshi, S. Qayyum, A. A. Nassani, A. M. Aldakhil, M. M. Q. Abro, and K. Zaman, "Management of various socio-economic factors under the United Nations sustainable development agenda," Resour. Policy, vol. 64, p. 101515, 2019. https://doi.org/10.1016/j.re sourpol.2019.101515

[3] M. I. Qureshi, N. U. Khan, A. M. Rasli, and K. Zaman, "The battle of health with environmental evils of Asian countries: promises to keep," Environ. Sci. Pollut. Res., vol. 22, no. 15, pp. 11708-11715, 2015. https://doi.org/10.1007/s11356-015-4440-8

[4] M. I. Qureshi et al., "Environment and air pollution: health services bequeath to grotesque menace,” Environ. Sci. Pollut. Res., vol. 22, no. 5, pp. 3467-3476, 2015. https://doi.org/ 10.1007/s11356-014-3584-2

[5] M. I. Qureshi, A. Md. Rasli, A. Jusoh, and T. O. Kowang, "Sustainability: A new manufacturing paradigm,” J. Teknol., vol. 77, no. 22, pp. 47-53, 2015. https://doi.org/10.11113/ jt.v77.6661

[6] A. M. Rasli, N. Norhalim, T. O. Kowang, and M. I. Qureshi, “Applying managerial competencies to overcome business constraints and create values: Evidence from small technology-based firms in Malaysia," J. Manag. Info, vol. 2, no. 2, pp. 22-28, 2015. https://doi. org/10.31580/jmi.v3i1.15

[7] M. I. Qureshi, M. Iftikhar, S. Y. Janjua, K. Zaman, U. M. Raja, and Y. Javed, "Empirical investigation of mobbing, stress and employees' behavior at work place: quantitatively refining a qualitative model," Qual. Quant., vol. 49, no. 1, pp. 93-113, 2015. https://doi.org/ $\underline{10.1007 / \mathrm{s} 11135-013-9976-4}$ 
[8] I. Q. Muhammad, B. Mansoor, K. Aamir, and Z. Khalid, "Measuring queuing system and time standards: A case study of student affairs in universities," African J. Bus. Manag., vol. 8, no. 2, pp. 80-88, 2014. https://doi.org/10.5897/ajbm2013.7247x

[9] M. I. Qureshi, M. N. Bhatti, A. M. Rasli, M. Yasir, and K. Zaman, "The Delphi method for internationalization of higher education in Pakistan: Integrating theory of constraints and quality function deployment,” Mediterr. J. Soc. Sci., vol. 5, no. 20, pp. 2702-2710, 2014. https://doi.org/10.5901/mjss.2014.v5n20p2702

[10] M. I. Qureshi, R. M. Yusoff, S. S. Hishan, A. F. Alam, K. Zaman, and A. M. Rasli, "Natural disasters and Malaysian economic growth: policy reforms for disasters management," Environ. Sci. Pollut. Res., vol. 26, no. 15, pp. 15496-15509, May 2019. https://doi.org/10. 1007/s11356-019-04866-z

[11] M. I. Qureshi et al., "Modeling Work Practices under Socio-Technical Systems for Sustainable Manufacturing Performance," Sustainability, vol. 11, no. 16, p. 4294, Aug. 2019. https://doi.org/10.3390/su11164294

[12] M. Shahverdi, K. Ismail, and M. I. Qureshi, "The effect of perceived barriers on social entrepreneurship intention in Malaysian universities: The moderating role of education," Manag. Sci. Lett., vol. 8, no. 5, pp. 341-352, 2018. https://doi.org/10.5267/j.msl.2018.4.01 $\underline{4}$

[13] Q. M. I. \& R. A. Harasis A. A., "Development of research continuous usage intention of ecommerce. A systematic review of literature from 2009 to 2015.," Int. J. Eng. Technol., vol. 7, no. 2.29 (2018), pp. 73-78, 2018. https://doi.org/10.14419/ijet.v7i2.29.13133

[14] M. I. Qureshi, R. M. Yusoff, A. R. Ahmed, K. Isa, and A. Imran, "Linking quality of work life with sustainable manufacturing performance,” Adv. Sci. Lett., vol. 23, no. 9, pp. 82328235, 2017. https://doi.org/10.1166/asl.2017.9867

[15] M. I. Qureshi, M. A. Hassan, S. S. Hishan, A. M. Rasli, and K. Zaman, "Dynamic linkages between sustainable tourism, energy, health and wealth: Evidence from top 80 international tourist destination cities in 37 countries," J. Clean. Prod., vol. 158, pp. 143-155, 2017. https://doi.org/10.1016/i.jclepro.2017.05.001

[16] M. I. Qureshi, U. Awan, Z. Arshad, A. M. Rasli, K. Zaman, and F. Khan, "Dynamic linkages among energy consumption, air pollution, greenhouse gas emissions and agricultural production in Pakistan: sustainable agriculture key to policy success," Nat. Hazards, vol. 84, no. 1, pp. 367-381, 2016. https://doi.org/10.1007/s11069-016-2423-9

[17] M. I. Qureshi, A. M. Rasli, and K. Zaman, "Energy crisis, greenhouse gas emissions and sectoral growth reforms: Repairing the fabricated mosaic," J. Clean. Prod., vol. 112, pp. 3657-3666, 2016. https://doi.org/10.1016/j.jclepro.2015.08.017

[18] Y. T. Sung, K. E. Chang, and T. C. Liu, "The effects of integrating mobile devices with teaching and learning on students' learning performance: A meta-analysis and research synthesis," Comput. Educ., vol. 94, pp. 252-275, Mar. 2016. https://doi.org/10.1016/j. compedu.2015.11.008

[19] M. Kearney, S. Schuck, K. Burden, and P. Aubusson, "Viewing mobile learning from a pedagogical perspective,” Res. Learn. Technol., vol. 20, no. 1, 2012. https://doi.org/10.34 02/rlt.v20i0.14406

[20] H. Heflin, J. Shewmaker, and J. Nguyen, "Impact of mobile technology on student attitudes, engagement, and learning," Comput. Educ., vol. 107, pp. 91-99, Apr. 2017. https ://doi.org/10.1016/j.compedu.2017.01.006

[21] A. Lepp, J. E. Barkley, and A. C. Karpinski, "The relationship between cell phone use and academic performance in a sample of U.S. college students," SAGE Open, vol. 5, no. 1, Jan. 2015. https://doi.org/10.1177/2158244015573169 
[22] G. Sun and J. Shen, "Facilitating social collaboration in mobile cloud-based learning: A teamworkas a service (TaaS) approach,” IEEE Trans. Learn. Technol., vol. 7, no. 3, pp. 207-220, Jul. 2014. https://doi.org/10.1109/tlt.2014.2340402

[23] J. M. Zydney and Z. Warner, "Mobile apps for science learning: Review of research," Comput. Educ., vol. 94, pp. 1-17, Mar. 2016.

[24] C. X. Navarro, A. I. Molina, M. A. Redondo, and R. Juárez-Ramírez, "Framework to Evaluate M-Learning Systems: A Technological and Pedagogical Approach,” Rev. Iberoam. Tecnol. del Aprendiz., vol. 11, no. 1, pp. 33-40, Feb. 2016.

[25] M. I. Qureshi, A. M. Rasli, and K. Zaman, “A New Trilogy to Understand the Relationship among Organizational Climate, Workplace Bullying and Employee Health," Arab Econ. Bus. J., vol. 9, no. 2, pp. 133-146, 2014. https://doi.org/10.1016/j.aebj.2014.05.009

[26] M. I. Qureshi, A. Khan, K. Zaman, and N. Khaqan, "Structural investigation of service quality in conventional and islamic banking in pakistan,” Int. J. Manag. Innov., vol. 6, no. 1, p. 84, 2014.

[27] M. I. Qureshi, S. Y. Janjua, K. Zaman, M. S. Lodhi, and Y. Bin Tariq, "Internationalization of higher education institutions: Implementation of DMAIC cycle," Scientometrics, vol. 98, no. 3, pp. 2295-2310, 2014. https://doi.org/10.1007/s11192-013-1163-9

[28] C. Troussas, M. Virvou, and E. Alepis, "Collaborative learning: Group interaction in an intelligent mobile-assisted multiple language learning system," Informatics Educ., vol. 13, no. 2, pp. 279-292, 2014. https://doi.org/10.15388/infedu.2014.08

[29] E. Martín and R. M. Carro, "Supporting the Development of Mobile Adaptive Learning Environments: A Case Study," IEEE Trans. Learn. Technol., vol. 2, no. 1, pp. 23-36, 2009. https://doi.org/10.1109/tlt.2008.24

[30] K. K. Fan, P. wei Xiao, and C. H. Su, "The effects of learning styles and meaningful learning on the learning achievement of gamification health education curriculum," Eurasia J. Math. Sci. Technol. Educ., vol. 11, no. 5, pp. 1211-1229, 2015. https://doi.org/10.12973/ eurasia.2015.1413a

[31] T. H. Brown and L. S. Mbati, "Mobile learning: Moving past the myths and embracing the opportunities," Int. Rev. Res. Open Distance Learn., vol. 16, no. 2, pp. 115-135, 2015. https://doi.org/10.19173/irrodl.v16i2.2071

[32] U. Teichler, "Academic mobility and migration: What we know and what we do not know," Eur. Rev., vol. 23, pp. S6-S37, 2015. https://doi.org/10.1017/s1062798714000787

[33] R. F. Kenny, C. L. Park, J. M. C. Van Neste-Kenny, P. Burton, and A. Qayyum, "Using self-efficacy to assess the readiness of nursing educators and students for mobile learning," Int. Rev. Res. Open Distance Learn., vol. 13, no. 3, pp. 277-296, 2012. https://doi.org/10. 19173/irrodl.v13i3.1221

[34] A. A. Medhanyie et al., "Health workers' experiences, barriers, preferences and motivating factors in using mHealth forms in Ethiopia," Hum. Resour. Health, vol. 13, no. 1, Jan. 2015. https://doi.org/10.1186/1478-4491-13-2

[35] M. T. Yang and W. C. Liao, "Computer-assisted culture learning in an online augmented reality environment based on free-hand gesture interaction," IEEE Trans. Learn. Technol., vol. 7, no. 2, pp. 107-117, 2014. https://doi.org/10.1109/tlt.2014.2307297

[36] M. Bower and D. Sturman, "What are the educational affordances of wearable technologies?," Comput. Educ., vol. 88, pp. 343-353, 2015. https://doi.org/10.1016/j.compedu.20 15.07.013

[37] T. Cochrane and L. Antonczak, "Implementing a mobile social media framework for designing creative pedagogies,” Soc. Sci., vol. 3, no. 3, pp. 359-377, 2014. https://doi.org/10. $\underline{3390 / \text { socsci3030359 }}$ 
[38] K. Scott and R. Benlamri, "Context-aware services for smart learning spaces," IEEE Trans. Learn. Technol., vol. 3, no. 3, pp. 214-227, 2010. https://doi.org/10.1109/tlt.2010.12

[39] I. Boticki, L. H. Wong, and C. K. Looi, "Designing technology for content-independent collaborative mobile learning," IEEE Trans. Learn. Technol., vol. 6, no. 1, pp. 14-24, 2013. https://doi.org/10.1109/tlt.2012.8

[40] M. Alemi, M. R. A. Sarab, and Z. Lari, "Successful learning of academic word list via MALL: Mobile assisted language learning,” Int. Educ. Stud., vol. 5, no. 6, pp. 99-109, 2012. https://doi.org/10.5539/ies.v5n6p99

[41] M. Sugimoto, “A mobile mixed-reality environment for children's storytelling using a handheld projector and a robot," IEEE Trans. Learn. Technol., vol. 4, no. 3, pp. 249-260, 2011. https://doi.org/10.1109/tlt.2011.13

[42] E. Soep, "The digital afterlife of youth-made media: Implications for media literacy education," Comunicar, vol. 19, no. 38, pp. 93-100, 2012. https://doi.org/10.3916/c38-2012-02$\underline{10}$

\section{Authors}

Nohman Khan Is a PhD student in UNIKL Business School, University of Kuala Lumpur, Malaysia. Author has interest in digital marketing area and has many research articles related to the field. For more detail contact him at nohman.khan@s.unikl.edu.my

Muhammad Imran Qureshi Is currently affiliated with Faculty of Technology Management and Technopreneurship, Universiti Teknikal Malaysia Melaka, Malaysia. Muhammad Imran Qureshi has interest in area of operations management and open innovation field. For more details contact him at.qureshi@utem.edu.my

Syed Muhammad Ahmad Hassan Gillani is currently a PhD candidate at Azman Hashim International Business School, University Teknologi Malaysia, Malaysia. He is also serving as lecturer at GC university Faisalabad Pakistan.

Hamad Raza currently a PhD candidate at Azman Hashim International Business School, University Teknologi Malaysia, Malaysia. He is also serving as lecturer at GC university Faisalabad Pakistan.

Article submitted 2020-01-30. Resubmitted 2020-03-02. Final acceptance 2020-03-03. Final version published as submitted by the authors. 